Research Article

\title{
Prediction of Mining Subsidence in Shallow Coal Seam
}

\author{
Gang Li and Qinghe Yang \\ Mining Institute, Liaoning University of Engineering and Technology, Fuxin 123000, China \\ Correspondence should be addressed to Qinghe Yang; qinghe_aiys@163.com
}

Received 14 September 2019; Accepted 20 January 2020; Published 19 February 2020

Academic Editor: Enrico Conte

Copyright (c) 2020 Gang Li and Qinghe Yang. This is an open access article distributed under the Creative Commons Attribution License, which permits unrestricted use, distribution, and reproduction in any medium, provided the original work is properly cited.

\begin{abstract}
Theoretical calculation, numerical simulation, and field measurement were combined to study the recovery of coal resources in the 5th pan area of Dianping Coal Mine without damaging surface buildings. A mathematical model was established to predict the settlement range and displacement of the surface after coal mining. The FLAC3D5.0 program was used to simulate the evolution law of the overburden strata under the coal mining conditions of the study area. The lateral influence range was $45.8 \mathrm{~m}$ and $42.4 \mathrm{~m}$, and the maximum surface subsidence was $2.604 \mathrm{~m}$ and $2.78 \mathrm{~m}$, respectively. The mining boundary of the 5-210 working face was designed using the result of the simulation program. Real-time dynamic observation data collected from 18 surface displacement monitoring points measured surface subsidence as $2.69 \mathrm{~m}$. The civil construction protection area was not deformed. The working face provided safe recovery of $1,471,446,000 \mathrm{~kg}$ of coal, resulting in significant economic and social benefits.
\end{abstract}

\section{Introduction}

Currently, coal serves as China's main energy source. Some statistics suggest that the coal buried under buildings, railways, and water bodies totals more than 14 trillion $\mathrm{kg}[1]$. With the rapid development of the national economy, the demand for coal has increased, and a large amount of coal has been extracted from the ground [2]. This has destroyed the original mechanical equilibrium state within the rock mass and deformed and destroyed the overburden rock to varying degrees. When the length and width of the minedout area exceed 0.2-0.3 times the average mining depth, the movement and deformation of the rock formation near the starting coal-mining site will extend to the surface [1]. Consequently, the surface movement and deformation will affect infrastructure, rivers, and pipelines, altering or even destroying them [3]. Therefore, studying surface subsidence in mined-out areas is of great significance.

Researchers worldwide have performed several studies on surface subsidence and its prediction in the mined-out area with remarkable results [4]. Some examples of the methods used in these studies are the typical curve method, profile function method [1], probability integration method [5] based on continuum mechanics, and influence function method [6-8]. However, these prediction methods are applicable only to specific conditions, and varying mined-out area conditions lead to unsatisfactory prediction results, which pose a significant challenge to scholars and technicians who study mining subsidence. Numerical simulations have an advantage in that because they are performed on a computer, conditions that cannot be reached by test methods can be applied. Zhao et al. employed FLAC3D to study the law of surface subsidence under the filling of villages [9]. Guo et al. used FLAC3D to analyze the law of surface movement and deformation under the condition of thick loose layer mining [10]. Deng et al. used numerical simulation to determine the surface subsidence boundary and surface collapse volume after mining in the mining area [11]. However, they did not combine theoretical calculation with field measurement and only applied numerical simulation prediction. To rectify this issue, in this study, the 5-210 working face of the Dianping Coal Mine was used as the engineering background, and theoretical calculation, numerical simulation, and field measurements were combined to more accurately predict the surface subsidence range of the mined-out area, which provides an important theoretical basis for coal mining and building safety. 


\section{Engineering Background}

The 5-210 working face is located south of the Dianping Coal Mine Industrial Plaza, Wangjiazhuang Village and Dianping Village; north of the Mata Village; and east of the Nanling Shangcun Village. The east-west strike length is $1465 \mathrm{~m}$, trend length is $240 \mathrm{~m}$, coal seam is nearly horizontal, bedrock is thin, coal thickness is $3.1 \mathrm{~m}$ on average, and average buried depth is $200 \mathrm{~m}$, which belong to the shallow buried coal seam. Because there are industrial squares and villages near the surface, it is necessary to rationally design the location of the 5-210 working face and recover coal resources as much as possible without affecting the stability of surface buildings.

\section{Mathematical Models}

3.1. Spatial Distribution of the Fallen Zone in the Mined-Out Area. For the modelling, the coordinate system of surface subsidence is established according to the theory of spatial analytic geometry and rock movement, as shown in Figure 1. The origin of the coordinate system is set at the centre of the mined-out area, which is the point of the maximum surface subsidence. The direction of the strike is taken as the $X$-axis. The direction of advance along the working plane is considered to be positive. The direction of the trend is taken as the $Y$-axis. The direction of the return air is positive. The transport direction is negative. The $Z$-axis is vertical sinking, and the boundary should satisfy the following:

$$
\frac{x^{2}}{a^{2}}+\frac{y^{2}}{b^{2}}=1
$$

where $a$ and $b$ are the basic parameters of the model, $a$ represents half the strike length, and $b$ represents half the trend length.

Sinking range condition:

$$
0 \leq \frac{x^{2}}{a^{2}}+\frac{y^{2}}{b^{2}} \leq 1 .
$$

3.1.1. Compaction Zone. When the local table subsidence point is within the range of $\left(\left(x^{2} /\left(\left(l_{z} / 2\right)-\right.\right.\right.$ $\left.\left.\left.\left(L_{z d}-L_{z s}\right)\right)^{2}\right)+\left(y^{2} /\left(\left(l_{q} / 2\right)-\left(L_{q d}-L_{q s}\right)\right)^{2}\right)\right) \leq 1$, and it lies in the compaction stability zone. This area is similar to the bottom of the "elliptical disk" in which the amount of surface subsidence is the same.

Here, $l_{z}$ is the strike length $(\mathrm{m}), l_{q}$ is the trend length $(\mathrm{m})$, $L_{z d}$ is the trend low stress zone length $(\mathrm{m}), L_{z s}$ is the trend stress increasing zone length $(\mathrm{m}), L_{q d}$ is the oriented lowstress zone length $(\mathrm{m})$, and $L_{q s}$ is the tendency to increase the length of the stress zone $(m)$.

3.1.2. Load-Affected Zone. When the local table sinks and is within the range of $\left(\left(x^{2} /\left(\left(l_{z} / 2\right)-\left(L_{z z}-L_{z y}\right)\right)^{2}\right)+\right.$ $\left.\left(y^{2} /\left(\left(l_{q} / 2\right)-\left(L_{q z}-L_{q y}\right)\right)^{2}\right)\right) \leq 1$ and $\left(\left(x^{2} /\left(\left(l_{z} / 2\right)-L_{z z}\right)^{2}\right)+\right.$ $\left.\left(y^{2} /\left(\left(l_{q} / 2\right)-L_{q y}\right)^{2}\right)\right) \leq 1$, it lies in the load-affected zone. This area is similar to the edge of the "elliptical disk." It can be equivalently converted to the coordinate system $x$ and $y$-axis at any point within this range. As shown in

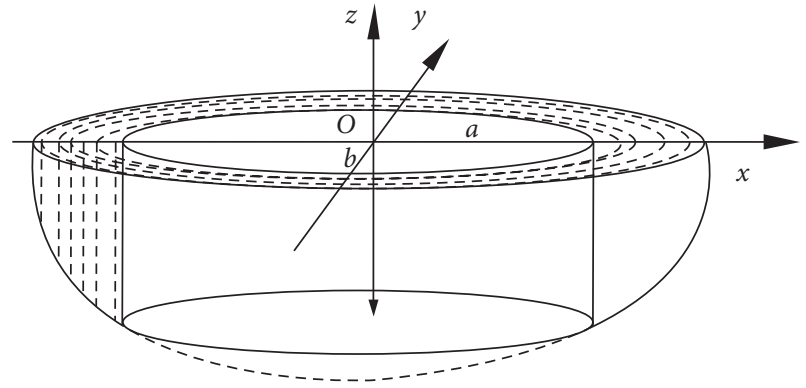

FIgURE 1: Surface subsidence coordinate system.

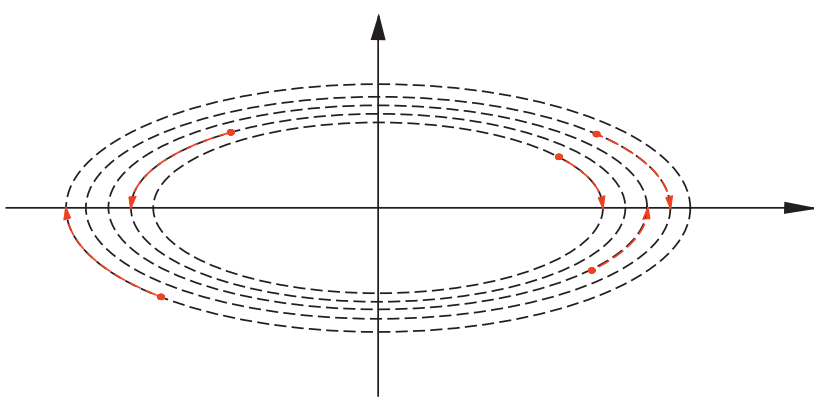

Figure 2: Schematic of coordinate transformation.

Figure 2, after transformation, the horizontal distance between the subsidence point and the coal wall can be obtained. The horizontal distance $L$ between the converted subsidence point and the coal wall was substituted into the expression of the crushing expansion coefficient in the loadaffected area to obtain the corresponding crushing expansion coefficient, which was finally substituted into the expression of surface subsidence to obtain the subsidence amount at this point.

Here, $L_{z z}$ is the strike length in the direction of the $Z$-axis (m), $L_{z y}$ is the strike length in the direction of the $Y$-axis (m), $L_{q z}$ is the trend length in the direction of the $Z$-axis $(\mathrm{m})$, and $L_{q y}$ is the trend length in the direction of the $Y$-axis $(m)$.

3.1.3. Natural Accumulation Area. When the local table sinking point is within the range of $\left(\left(x^{2} /\left(\left(l_{z} / 2\right)-L_{z z}\right)^{2}\right)+\right.$ $\left.\left(y^{2} /\left(\left(l_{q} / 2\right)-L_{q y}\right)^{2}\right)\right) \leq 1$ and $\left(\left(x^{2} /\left(l_{z} / 2\right)^{2}\right)+\left(y^{2} /\left(l_{q} / 2\right)^{2}\right)\right)$ $\leq 1$, it lies in the natural accumulation area. Within this range, the rock mass in the fallen belt is not completely collapsed, and a residual cantilever beam structure is formed near the coal wall side, which supports the overlying sand layer. Only weak subsidence occurs under the load of the overlying sand layer.

3.2. Fragmentation Coefficient and Surface Subsidence. The rock fragmentation coefficient is the ratio of the volume of the rock in its loose state after crushing to the volume of the rock in its whole state before crushing. The volume of the broken rock will be larger than that of the whole rock. The stress of the rock mass in the stress-stationary zone is calculated according to the rock column method. The physical and mechanical parameters of the overburden are as follows: 
the overburden bedrock is $17 \mathrm{~m}$ thick, and the sand layer in the overburden is approximately $30 \mathrm{~m}$ thick. The bulk density of the sand is $18.5 \mathrm{kN} / \mathrm{m}^{3}$. The average bulk density of the bedrock layer is $23.5 \mathrm{kN} / \mathrm{m}^{3}$. The internal friction angle of the sand layer is $27^{\circ}$.

3.2.1. Surface Subsidence in the Compacted Stable Area. The stress load of the overburden old roof and sand layer is calculated as follows:

$$
\sigma_{z p}=h_{j} \gamma_{j}+h_{s} \gamma_{s}\left[1-\frac{h_{s} \tan ^{2}\left(45^{\circ}-\left(\varphi_{s} / 2\right)\right) \tan \varphi_{s}}{2 a}\right],
$$

where $\gamma_{s}$ is the average bulk density of the sand layer $\left(\mathrm{kN} / \mathrm{m}^{3}\right), \gamma_{j}$ is the average bulk density of the bedrock layer $\left(\mathrm{kN} / \mathrm{m}^{3}\right), h_{s}$ is the thickness of the sand layer $(\mathrm{m}), h_{j}$ is the thickness of the bedrock layer $(\mathrm{m}), \varphi_{s}$ is the internal friction angle of the sand layer $\left({ }^{\circ}\right)$, and $\sigma_{z p}$ is the stress load ( $\left.\mathrm{MPa}\right)$.

Data are input into the overburden rock stress formula (3) of the fallen rock mass, and the result of the calculation is $0.9523 \mathrm{MPa}$.

According to the theory of full-face subsidence model in [6], because the coal seam is nearly horizontal, the halflength is used instead of a. Therefore, the value of $2 \mathrm{a}$ is $1465 \mathrm{~m}$.

The mined area of the 5-210 working face of the mine is selected as the research object. According to the engineering analogy method, the relevant data are determined, and the stress load of the mudstone layer and the sandstone layer in the collapse zone of the compaction zone is substituted into the stress-swelling coefficient relationship:

$$
\begin{aligned}
& k_{s}=a-b \ln \left(\sigma_{z p}+0.466\right), \\
& k_{n}=a-b \ln \left(\sigma_{z p}+0.651\right),
\end{aligned}
$$

where $k_{s}$ is the swell coefficient of sandstone, $k_{n}$ is the swell coefficient of mudstone, and $a$ and $b$ are regression coefficients.

Substituting the experimental data into the formula, the coefficients of collapse of the rock mass in the range of the compaction stability zone are found to be $1.012\left(k_{n}\right)$ and $1.008\left(k_{n}\right)$.

$$
W=M-\sum h_{i}\left(k_{i}-1\right),
$$

where, $W$ is the surface subsidence $(\mathrm{m}), M$ is the coal mining thickness $(\mathrm{m}), h_{i}$ is the fall zone thickness of each rock layer (m), and $k_{i}$ is the coefficient of expansion of each rock layer in the fallen zone.

The coefficient of the expansion of each rock layer in the depression zone of the compaction zone and the thickness of each rock layer are substituted into the equation of surface subsidence in the shallow abandoned mined-out area (6), and the surface subsidence of the compaction zone $(W)$ is found to be $2.604 \mathrm{~m}$.

3.2.2. Surface Subsidence in Areas with Increased Stress. The sum of the bedrock and the overlying sand layer in the fracture zone of the stress-increasing zone is the sum of the stress of the fallen rock mass and the gravity of the fallen rock mass, which is, respectively, substituted into the sandstone and mudstone stress-swelling coefficient fitting formula. The relationship between the coefficient of expansion of sandstone and mudstone in the stress-rise area and the boundary distance of the mined-out area is obtained:

$$
\begin{aligned}
k_{s}= & 1.137-0.358 \times \ln \left[q \left[\operatorname { e x p } ( - ( L - L _ { d } ) \sqrt [ 4 ] { \frac { k _ { g } } { 4 E I } } ) \left(\frac{\sqrt[4]{\left(k_{g} / 4 E I\right)}-\sqrt[4]{\left(k_{c} / 4 E I\right)}}{\sqrt[4]{\left(k_{g} / 4 E I\right)}+\sqrt[4]{\left(k_{c} / 4 E I\right)}} \sin \left(\left(L-L_{d}\right) \sqrt[4]{\frac{k_{g}}{4 E I}}\right)\right.\right.\right. \\
& \left.\left.\left.-\cos \left(\left(L-L_{d}\right) \sqrt[4]{\frac{k_{g}}{4 E I}}\right)\right)+1\right]+0.466\right], \\
k_{n}= & 1.18-0.364 \times \ln \left[q \left[\operatorname { e x p } \left(-\left(L-L_{d}\right) \sqrt[4]{\left.\frac{k g}{4 E I}\right)}\left(\frac{\sqrt[4]{\left(k_{g} / 4 E I\right)}-\sqrt[4]{\left(k_{c} / 4 E I\right)}}{\sqrt[4]{\left(k_{g} / 4 E I\right)}+\sqrt[4]{\left(k_{c} / 4 E I\right)}} \sin \left(\left(L-L_{d}\right) \sqrt[4]{\frac{k_{g}}{4 E I}}\right)\right.\right.\right.\right. \\
& \left.\left.\left.-\cos \left(\left(L-L_{d}\right) \sqrt[4]{\frac{k_{g}}{4 E I}}\right)\right)+1\right]+0.651\right],
\end{aligned}
$$

where $k_{s}$ and $k_{n}$ are the coefficients of expansion of sandstone and mudstone, respectively $(\mathrm{kg}), k_{c}$ is the rock mass of the fallen rock and coal seam $\left(\mathrm{GN} / \mathrm{m}^{3}\right), L_{d}$ is the length of the low-stress zone $(\mathrm{m}), E$ is the elastic modulus of the bedrock
(GPa), and $I$ is the moment of inertia of the bedrock beam $\left(\mathrm{m}^{4}\right)$.

The surface subsidence increases with the distance between the stress-rise zone and the coal pillar. When the 
overburden falls to the base rock stratum, the rate of change of surface subsidence and coal pillar distance suddenly decreases, and the final subsidence is the same as the subsidence of the compaction zone, which is approximately $2.6 \mathrm{~m}$.

3.2.3. Natural Accumulation Area Subsidence. In this range, the stress of the fallen rock mass is small, it is loosely accumulated, and the coefficient of collapse is the largest. A previous study provides the relationship between the coefficient of collapse of the rock mass and the position of the coal wall in the loose accumulation area [6]:

$$
k z=c \ln \left(b \sqrt{1+\frac{L^{2}}{a}}+\Delta c\right)+d
$$

where $k_{z}$ is the natural accumulation zone rock fragmentation coefficient, $c$ and $d$ are regression coefficients, and $\Delta c$ is a compensation parameter.

The rock mass in the fallen belt is not completely collapsed, and a residual cantilever beam structure is formed near the side of the coal wall. This supports the overlying sand layer, and only weak subsidence is generated under the load of the overlying sand layer.

In summary, the surface subsidence in the central compaction zone of the mined-out area is the largest, reaching $2.604 \mathrm{~m}$.

3.3. Surface Movement Range. Owing to the variations in the overburden morphology, the internal stress field also sharply varies, and the rock formation is finally destroyed. When the tensile deformation exceeds the ultimate deformation of the overburden, a small subsidence will also occur in the peripheral region of the mined-out area. Using the movement data of the mining face boundary, the boundary angle of the sand and bedrock layers is derived, and finally, it is brought into the geological condition of the 5-210 working face to calculate the surface movement range. The coal mine safety regulations require a safety standard of surface settlement of $10 \mathrm{~mm}$, and the boundary point is a position where the surface subsidence is $10 \mathrm{~mm}$. The angle between the boundary of the coal seam and the horizontal line is called the comprehensive boundary angle.

\subsubsection{Sand Layer and Bedrock Boundary Moving Angle.} According to the hydrogeological data and error principle, the condition equation is obtained, and the moving angle calculation condition is shown in Figure 3.

Let the sand layer tend to move at an angle of $\alpha$ and the bedrock tend to move at an angle of $\beta$. Thus,

$$
L=h \operatorname{ctg} \alpha+H \operatorname{ctg} \beta \text {, }
$$

where $L$ is the horizontal distance from the position where the surface drops by $10 \mathrm{~mm}$ to the boundary of the coal seam gob $(\mathrm{m}), h$ is the thickness of the sand layer $(\mathrm{m})$, and $H$ is the base rock layer thickness $(m)$.

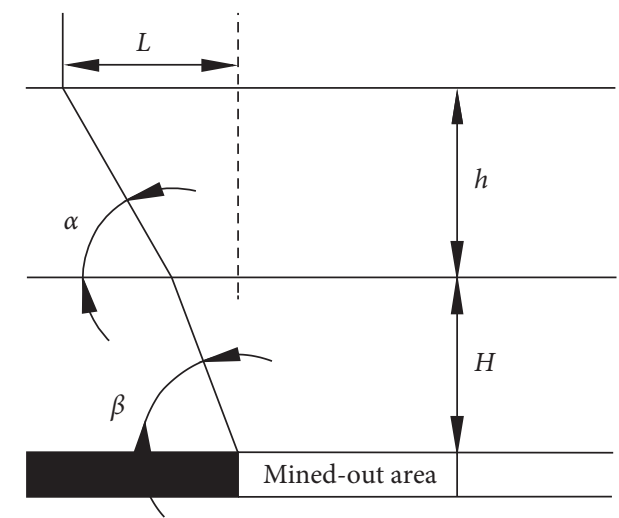

FIgURE 3: Conditions under which the moving angle is calculated.

Through on-site monitoring, the two sets of working surface boundary movement data are obtained; $L_{1}, h_{1}, H_{1}, L_{2}$, $h_{2}$, and $H_{2}$ are $24.7 \mathrm{~m}, 21.7 \mathrm{~m}, 36.3 \mathrm{~m}, 28.3 \mathrm{~m}, 28.1 \mathrm{~m}$, and $30.0 \mathrm{~m}$, respectively. Substituting the data into the conditional equation, the sand layer tends to move at an angle $\alpha$ of $52^{\circ}$ and the bedrock layer at an angle $\beta$ of $78^{\circ}$.

3.3.2. Surface Movement Range Calculation. The horizontal distance from the mining boundary to the subsidence of $10 \mathrm{~mm}$ is set as $L_{q}$. Then, knowing the thickness of the sand layer, the bedrock layer, and its moving angle, the data can be substituted to obtain the value of $L_{q}$ as $45.8 \mathrm{~m}$.

\section{FLAC3D Simulation of Surface Subsidence}

4.1. Model Construction. FLAC3D is simulation software developed by ITASCA. It is an extension of the two-dimensional finite difference program FLAC2D, which can simulate the mechanical characteristics of three-dimensional structures of soil, rock, and other materials and analyze their plastic flows. According to the geological conditions of the coal seam in the 5-210 working face of the Dianping Coal Mine, the numerical simulation calculation model is constructed as shown in Figure 4. The model is $800 \mathrm{~m}$ long, $400 \mathrm{~m}$ wide, and $300 \mathrm{~m}$ high. The average buried depth of the ore body is $200 \mathrm{~m}$, whose thickness is $3.1 \mathrm{~m}$. The working face has a length of $240 \mathrm{~m}$ and a pushing length of $500 \mathrm{~m}$. The model uses the Mohr-Coulomb calculation criterion, and the selected rock mechanics parameters are listed in Table 1. The upper surface of the model is a stress boundary. The upper part of the coal seam is simulated with the overlying strata of $200 \mathrm{~m}$. A load of $5 \mathrm{MPa}$ is applied on the upper boundary of the model. The self-weight boundary of the overlying strata is simulated. The constraint conditions are the sliding supports that limit the horizontal displacement on both sides. The bottom is a fixed support that limits displacement in the vertical and horizontal directions. The model is divided into 126,198 grid nodes and 118,400 isoparametric nodes.

The numerical modelling steps are as follows. First, the top and bottom rock strata of the coal seam and the 5-210 working face are grouped to allow the numerical model to balance for the first time. Second, the mechanical parameters 

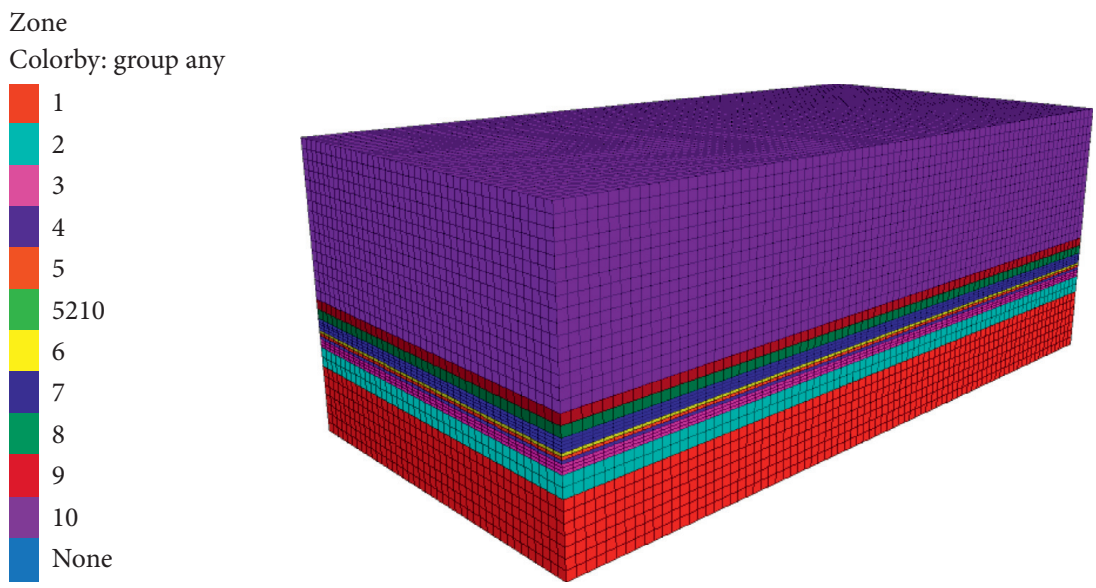

FIgURE 4: Numerical simulation model.

Table 1: Physical and mechanical properties of coal and rock.

\begin{tabular}{|c|c|c|c|c|c|c|}
\hline $\begin{array}{l}\text { Rock } \\
\text { formation }\end{array}$ & $\begin{array}{c}\text { Tensile strength } \sigma t \\
(\mathrm{MPa})\end{array}$ & $\begin{array}{c}\text { Cohesion } C \\
(\mathrm{MPa})\end{array}$ & $\begin{array}{c}\text { Internal friction angle } \\
\varphi\left({ }^{\circ}\right)\end{array}$ & $\begin{array}{l}\text { Bulk modulus } \mathrm{K} \\
(\mathrm{GPa})\end{array}$ & $\begin{array}{c}\text { Shear modulus } G \\
(\mathrm{GPa})\end{array}$ & $\begin{array}{c}\text { Poisson' ratio } \\
\mu\end{array}$ \\
\hline Topsoil & 0.48 & 0.51 & 34 & 0.83 & 0.46 & 0.27 \\
\hline Bedrock & 2.0 & 2.42 & 39 & 4.2 & 2.6 & 0.26 \\
\hline Limestone & 1.77 & 2.02 & 40 & 4.00 & 2.40 & 0.25 \\
\hline Mudstone & 0.93 & 1.07 & 35 & 2.29 & 1.06 & 0.30 \\
\hline $\begin{array}{l}\text { Fine } \\
\text { sandstone }\end{array}$ & 1.40 & 2.73 & 42 & 8.15 & 4.43 & 0.27 \\
\hline Mudstone & 0.93 & 1.07 & 35 & 2.29 & 1.06 & 0.30 \\
\hline No. 5 coal & 1.10 & 1.60 & 38 & 4.18 & 1.40 & 0.35 \\
\hline Mudstone & 0.93 & 1.07 & 35 & 2.29 & 1.06 & 0.30 \\
\hline $\begin{array}{l}\text { Fine } \\
\text { sandstone }\end{array}$ & 1.40 & 2.73 & 42 & 8.15 & 4.43 & 0.27 \\
\hline Limestone & 1.77 & 2.02 & 40 & 4.00 & 2.40 & 0.25 \\
\hline
\end{tabular}

of the rock layer are assigned to the model for calculation. After the model is balanced two times, the long wall panel is removed and then solved. Third, once the roof of the coal seam has naturally collapsed, the mined-out area is compacted and the calculation is stopped. The surface subsidence range can then be observed through the numerical simulation results.

Rock mass is composed of rock blocks and structural planes. Therefore, to study the mechanical properties of rock masses, we must first study their mechanical properties. Furthermore, under certain conditions (such as a lack of structural planes in the rock mass or the rock mass being monolithic or massive), the deformation and strength properties of the rock blocks can often be used to approximate the deformation and strength properties of the rock mass. At this time, the nature of the rock blocks is relatively close to that of the rock mass. The mechanical properties of the rock blocks can often be used to extrapolate the mechanical properties of the rock mass and solve the rock mass mechanics problems.

By testing the rock samples excavated underground, it was found that the structural surface of the coal seam top and bottom layers was not developed, so the mechanical parameters of the rock blocks were measured using an indoor rock block test method. To ensure the reliability of the data, multiple sets of samples need to be collected and a large number of tests need to be performed. After analyzing the data, the final results were used to approximate the mechanical parameters of the rock mass, as shown in Table 1. These parameters are used for numerical modelling to simulate the surface subsidence range.

4.2. Dianping Coal Mine 5-210 FLAC3D Simulation Results. According to the simulation model developed above and the structural parameters of the coal mining site, the lateral influence range and the maximum subsidence of the minedout area in the 5-210 working face are obtained (Figures 5-7). The coalmine safety regulations (construction, water body, railway and main well coal pillar retention, and coal mining specifications) indicate that, to ensure stability of surface buildings and coal mining safety, the ground settlement safety standard should be $10 \mathrm{~mm}$.

Figure 7 shows that the maximum value of surface subsidence is $2.78 \mathrm{~m}$. According to the 1:800 scale in Figure 7 , the lateral impact range of the budget surface is $42.4 \mathrm{~m}$. The reasonable boundary of the 5-210 working face layout is obtained, which is placed outside the influence range of the subsidence to ensure the stability of the surface building and 
Contour of $Z$-displacement
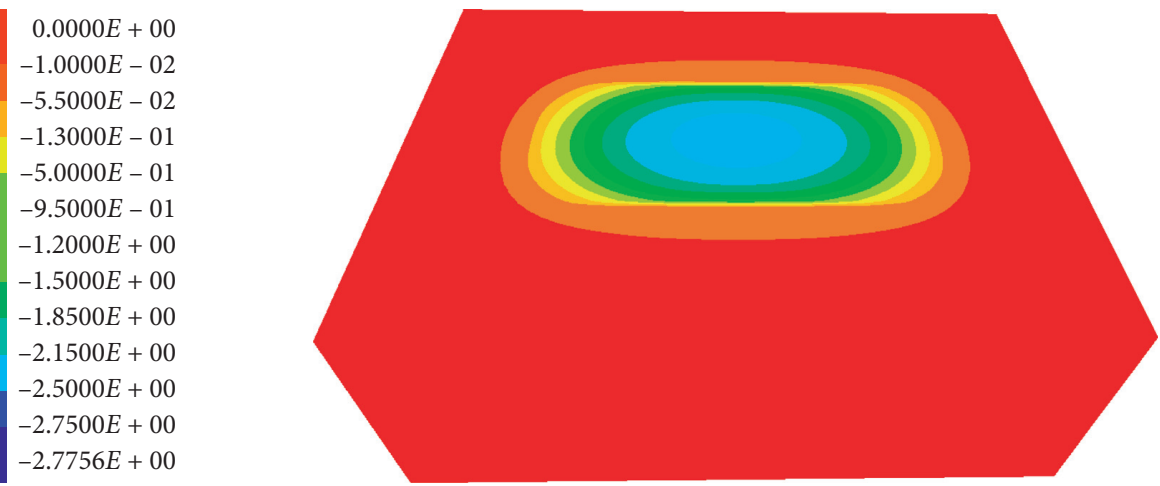

FIGURE 5: Numerical simulation of surface subsidence.

Contour of $Z$-displacement

Deformed factor: 100

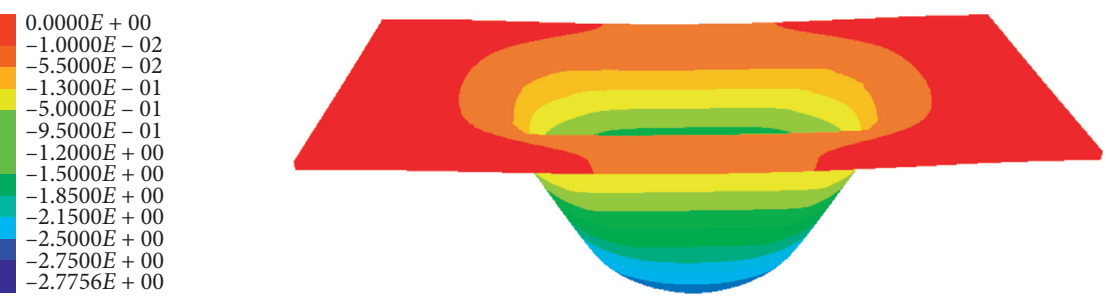

FIGURE 6: Stereogram of surface subsidence range.

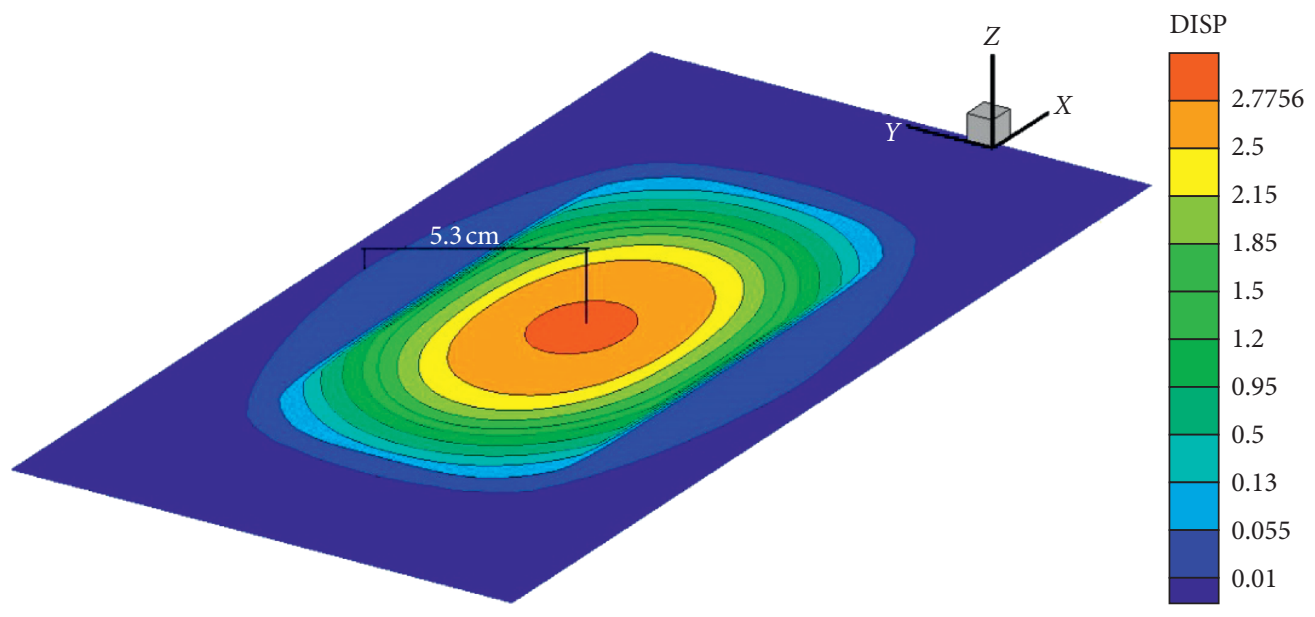

FIGURE 7: Surface subsidence contour map.

the safety of coal mining and to recover the coal resources to the greatest extent possible.

\section{Engineering Applications}

5.1. 5-210 Working Face Design. According to the results of the theoretical calculation, numerical simulation, and geological conditions of the coal mine, the 5-210 working face is arranged in the south wing of the 830 level, which is the seventh mining face of No. 5 coal in the second mining area; the west is connected with the 830 south wing belt lane, and the east to the well-field boundary, both north and south.

5.2. Observation Point Arrangement and Analysis of Test Results. According to the actual situation above the working surface, 18 monitoring points are arranged, and the data acquisition uses the Shanghai Hua test GPS receiver (nominal horizontal accuracy: $5 \pm 1 \mathrm{ppm}$, vertical accuracy: $10 \pm 2$ ppm, as per real-time kinematic dynamic observations). Two control points are arranged in an open area 1$2 \mathrm{~km}$ away from the influence range of the working face. 


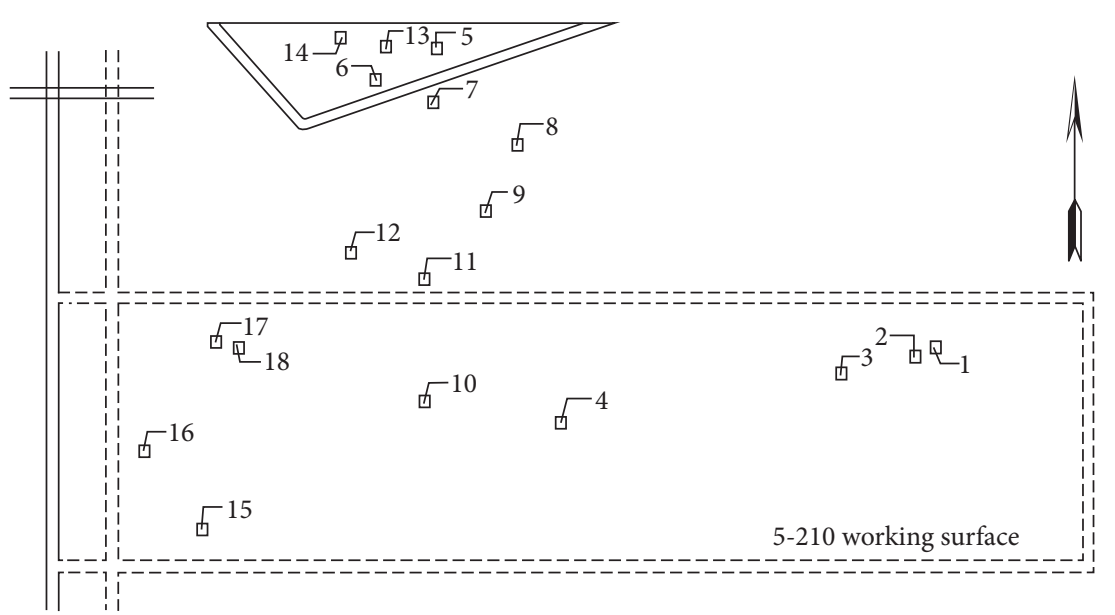

FIGURE 8: Layout of points to measure surface rock movement in the 5-210 working face.

These points are used to set up base stations, reset local coordinates, and check each time for daily measurement, and the contour map of the surface is obtained. The scale is $1: 18000$, as shown in Figure 8 .

The coordinates of each measuring point are listed in Table 2 .

On June 7, 2016, the monitoring began when the mining position of the working face was close to the test area. On December 20, 2016, the mining of the working face ended. The surface subsidence deformation was continuously monitored until April 3, 2017. The subsidence deformation no longer occurred in the displacement of surface measuring points, and the test was completed. During the monitoring process, measuring point 10 failed to measure displacement in the farmland. When measuring point 12 was tested on October 17, 2016, the cracks in the ground surface resulted in a collapse, and no data could be obtained for the remainder of the monitoring period. The maximum settlement at measuring point 1 was approximately $0.813 \mathrm{~m}$, and the maximum sinking amount at measuring point 2 was $1.032 \mathrm{~m}$. Measuring point 3 showed a tendency to be stable after August 9, with a maximum sinking amount of $1.951 \mathrm{~m}$. The maximum sinking amount at measuring point 4 was $2.690 \mathrm{~m}$. Measuring points $5-8$ were less affected by the mining. Measuring points $5,6,7$, and 8 recorded sinking amounts of $6 \mathrm{~mm}, 8 \mathrm{~mm}, 9 \mathrm{~mm}$, and $10 \mathrm{~mm}$, respectively. Measuring point 9 tended to indicate the first stable stage when the measured point on the working face passed $200 \mathrm{~m}$, and the subsidence was $0.2 \mathrm{~m}$. After the working face had advanced to $600 \mathrm{~m}$, it finally attained stability. The maximum sinking amount was $0.243 \mathrm{~m}$ at this time. Measuring points 11 and 12 were located at the edge of the working surface, and the stability time of surface subsidence was almost synchronous. The final sinking amount at measuring point 12 was $0.8936 \mathrm{~m}$ (no data were obtained in the later stages) and that at measuring point 11 was $1.462 \mathrm{~m}$. The sinking amounts at measuring points 13 and 14 were approximately $5-10 \mathrm{~mm}$. The final sinking amounts at measuring points $15,16,17$, and 18 were $0.512 \mathrm{~m}, 0.256 \mathrm{~m}$, $1.112 \mathrm{~m}$, and $1.415 \mathrm{~m}$, respectively.
TABLE 2: Surface coordinates.

\begin{tabular}{lccc}
\hline Serial no. & $X$ & $Y$ & $H(\mathrm{~m})$ \\
\hline 1 & 4172644.619 & 19509241.674 & 1167.154 \\
2 & 4172580.503 & 19509235.623 & 1170.793 \\
3 & 4172522.206 & 19509231.991 & 1172.029 \\
4 & 4172472.163 & 19509210.428 & 1178.606 \\
5 & 4172883.639 & 19509101.848 & 1122.005 \\
6 & 4172830.057 & 19509064.610 & 1131.076 \\
7 & 4172773.701 & 19509056.877 & 1153.525 \\
8 & 4172734.645 & 19509055.194 & 1163.832 \\
9 & 4172671.324 & 19509065.321 & 1178.640 \\
10 & 4172503.282 & 19509068.611 & 1196.891 \\
11 & 4172524.321 & 19508985.423 & 1198.122 \\
12 & 4172606.859 & 19508982.142 & 1179.248 \\
13 & 4172867.668 & 19509056.169 & 1113.982 \\
14 & 4172886.065 & 19509033.708 & 1086.624 \\
15 & 4172372.216 & 19508692.998 & 1093.322 \\
16 & 4172444.982 & 19508661.130 & 1088.462 \\
17 & 4172533.772 & 19508695.925 & 1091.232 \\
18 & 4172525.571 & 19508751.805 & 1107.895 \\
\hline
\end{tabular}

The simulation results of the surface subsidence are processed twice and combined with the 5-210 work surface layout, as shown in Figure 9.

The figure shows the surface subsidence range, and measuring points $1-4$ are within the influence range, wherein measuring point 4 is the maximum sinking point of the 5-210 working face, measuring points 5-8 are located near the industrial square and are not within the influence range, and the sinking curves of measuring points $1-8$ are shown in Figures 10 and 11. The "Coal Mine Regulations" stipulate that the protection zone of the industrial square should be provided with a $15 \mathrm{~m}$ wide retaining belt. Some distance still exists from the edge of the subsidence to the retaining belt to ensure the stability of the industrial square and the building.

The surface subsidence range map and sinking curve of the measuring point indicate that measuring points $5-8$ are stable in the industrial square of the Dianping Coal Mine. Further, 


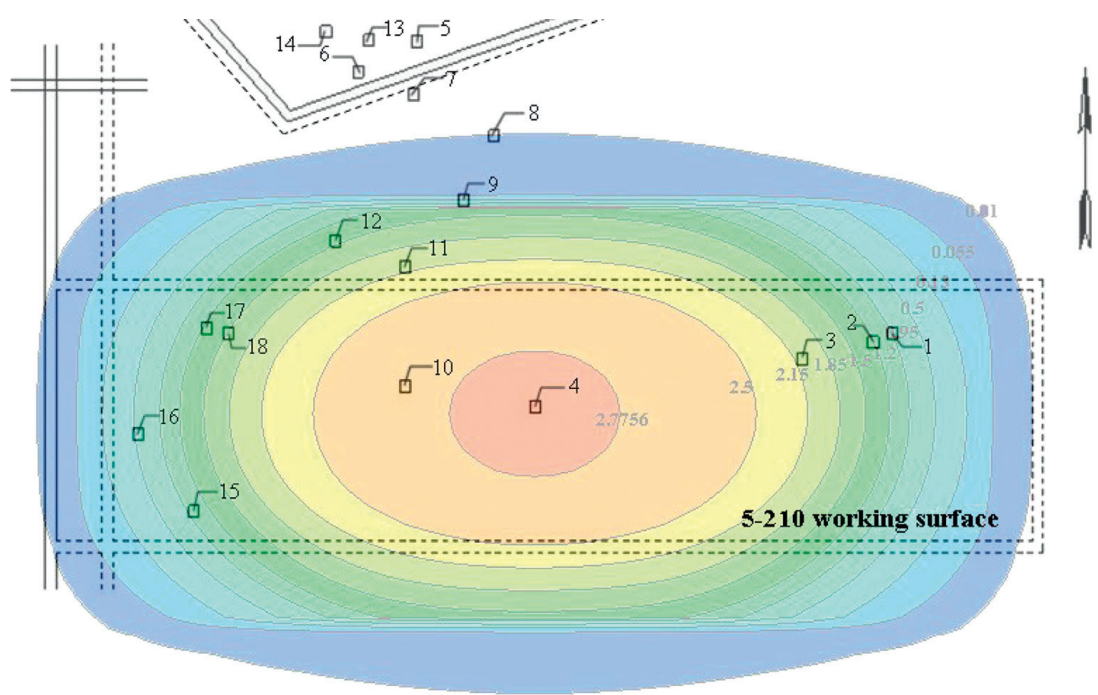

FIgURe 9: Surface subsidence area.

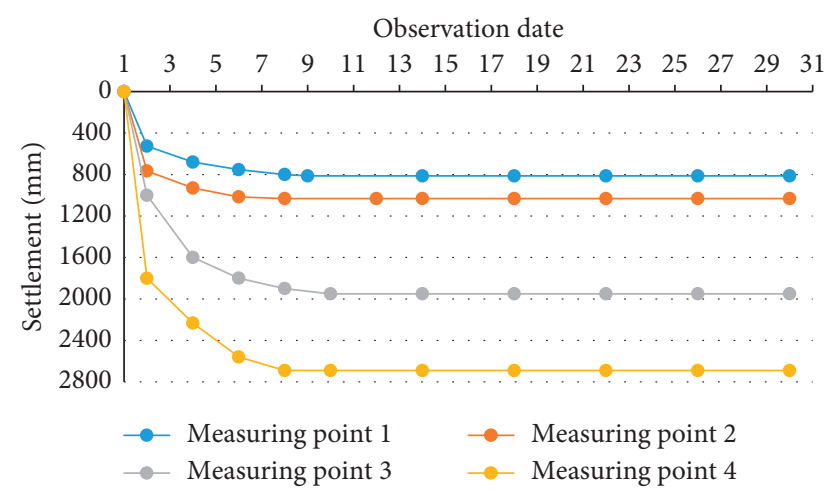

FIGURE 10: Subsidence curves of measuring points 1-4.

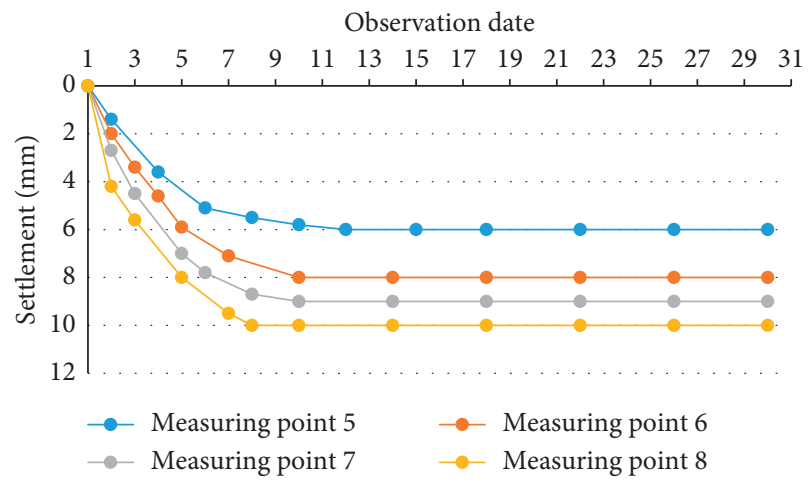

FIGURE 11: Subsidence curves of measuring points 5-8.

the sinking amount does not exceed the safety standard of the surface settlement $(10 \mathrm{~mm})$, ensuring the safety of the surface building (i.e., it is not affected by the mining of the 5-210 working face). Hence, the layout of the 5-210 working face is reasonable. This method can also guide the layout of the subsequent working face of the Dianping Coal Mine. The results of the theoretical calculations, numerical simulations, and field measurements are presented in Figure 12.

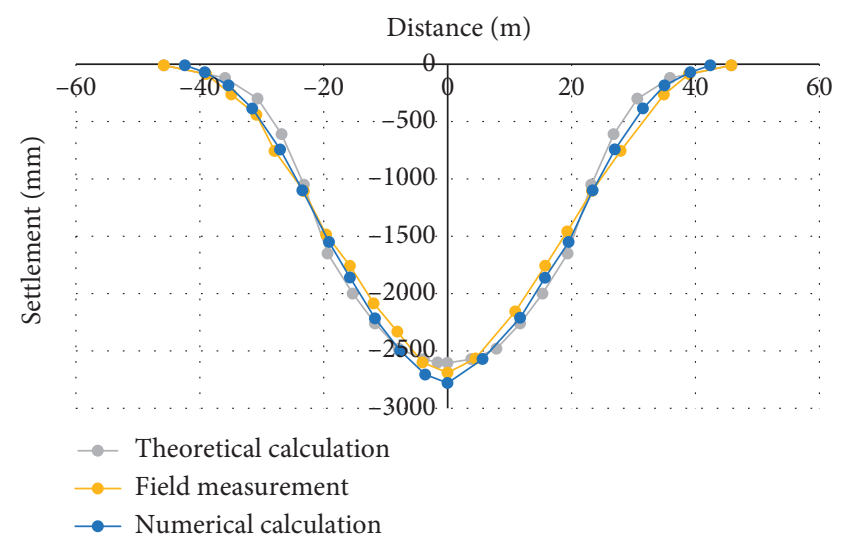

Figure 12: Subsidence curves of the theoretical calculations, numerical simulations, and field measurements.

\section{Conclusion}

After mining the No. 5 coal seam in the Dianping Coal Mine, the surface subsides with the periodic cutting of the coal seam roof, and the surface subsidence time is delayed by $13 \mathrm{~h}$ compared with the roof period of the coal seam mining.

After the coal seam is mined, the maximum subsidence of the surface is $2.69 \mathrm{~m}$, which is $86.8 \%$ the thickness of the coal seam. According to the safety regulations of the "three mining rules" in China, the critical value of deformation is $10 \mathrm{~mm}$, and the lateral influence distance of the surface subsidence is $45.8 \mathrm{~m}$.

This study combines a theoretical calculation and a numerical simulation to design the mining boundary of the 5-210 working face of the mine. After the field mining practice, the rationality of the scheme is verified.

Combining numerical modelling with in situ observations and/or measurements is crucial in determining and better understanding the mechanisms of rock mass behaviour, which greatly aids surface subsidence prediction. 
However, given that geological conditions can vary from one site to another, the method presented in this paper cannot be applied to all coal mines. Therefore, in the future, complex geological conditions such as faults should be taken into account to further improve the research method.

\section{Data Availability}

The data used to support this study are available from the corresponding author upon request.

\section{Conflicts of Interest}

The authors declare that there are no conflicts of interest regarding the publication of this paper.

\section{Acknowledgments}

This study was funded by the National Natural Science Foundation of China as a subsidized project (51774165 and 51704139) and by the Liaoning Provincial Department of Education, which serves local projects (LJ2017FAL014).

\section{References}

[1] D. Xie, T. Feng, J. Yuan, C. Huang, and J. Liu, "Mining method and surface subsidence prediction," Journal of Mining \& Safety Engineering, vol. 24, pp. 470-472, 2007.

[2] J. Wang, Y. Li, and L. Sun, "Prediction of surface movement deformation in goaf," Mining Safety and Environmental Protection, vol. 40, pp. 5-11, 2013.

[3] H. Pang and L. Xu, "Research on prediction method of surface subsidence in mining area based on FLAC3D," Coal Technology, vol. 37, pp. 204-206, 2018.

[4] P. Polanin, A. Kowalski, and A. Walentek, "Numerical simulation of subsidence caused by roadway system," Archives of Mining Sciences, vol. 64, no. 2, pp. 385-397, 2019.

[5] Y. Zou, K. Deng, and W. Ma, Mining Subsidence Engineering, China University of Mining and Technology Press, Xuzhou, China, 2003.

[6] Y. Hao, L. Hao, and H. Dai, "Establishing surface subsidence prediction model with elastic plate theory," Journal of Rock Mechanics and Geotechnical Engineering, vol. 25, no. Supplement, pp. 2958-2962, 2006.

[7] J. Wang, D. Li, and H. Ma, "Study on rheological mechanics model of mine pillar-top plate system in goaf," Journal of Rock Mechanics and Geotechnical Engineering, vol. 29, pp. 578-582, 2010.

[8] Z. Yang, "Boundary value method for prediction of surface subsidence in coal seam underground mining," Geotechnical, vol. 31, no. Supplement, pp. 232-236, 2010.

[9] W. Zhao, Z. Wang, and L. Sun, "Numerical simulation of surface subsidence in mining under village," Journal of Beijing Institute of Industry and Technology, vol. 17, pp. 29-33, 2018.

[10] Y. Guo, F. Meng, and J. Chen, "Numerical simulation analysis of surface subsidence under thick loose mining conditions," Coal Eng., vol. 46, pp. 103-105, 2014.

[11] X. Deng, L. Li, and Y. Tan, "Numerical simulation of surface subsidence induced by underground mining in mines," Safety in Coal Mines, vol. 49, no. 7, pp. 188-192, 2018. 